\title{
Initial Fatigue Life Estimation of Welded Structural Components
}

\author{
Mirko MAKSIMOVIC, Katarina MAKSIMOVIC, Dragi STAMENKOVIC, Ivana VASOVIC MAKSIMOVIC*
}

\begin{abstract}
Numerical modelling of welding process of two cylindrical tubes subjected to cyclic loads of constant amplitude is presented. For that purpose the Finite Element Method (FEM) was used for determination of thermo-mechanical behaviour and evaluation of welded joint residual stresses. In this investigation an efficient computation method for initial fatigue life estimation of welded structural components has been developed. Computation method with corresponding computation procedure is based on finite element numerical simulations of the thermal and stress analyses. As measure of fatigue resistance of welded structural elements, estimated values of low cycle fatigue life were used. Estimation of damages up to crack initiation in the welded joints of two cylindrical tubes was performed using SWT (Smith-Watson-Topper) relations. Present computation results are compared with corresponding experimental results of welded structural components. Obtained computation results of initial fatigue life estimation of welded structural element are in good agreement with experimental results.
\end{abstract}

Keywords: cylindrical tube; fatigue life estimation; finite elements; numerical simulations; welded structures

\section{INTRODUCTION}

Welding is one of the most applied techniques in the world for joining still structural components. Welds are liable to the phenomenon of fatigue, which is primarily the formation of initial crack and consequently reduction of strength to the action of varying loads. Fatigue is one of the main causes of failure in steel structures. The aim of this work is to do fatigue life estimation of welded structural components under cyclic loads. Since the consequence of the welding process is the appearance of residual stresses, it is necessary to determine them precisely. Numerical simulations of the welding process using FEM represent an unavoidable method nowadays [1-3]. Welded constructions are usually exposed to cyclic loads.

Therefore, the precise determination of residual stresses is important for the assessment of initial fatigue life of the welded structural elements. The subject of this paper itself is connected to the fatigue resistance of the welded structural elements, where FEM is used for the determination of the residual stresses and for all mechanical analyses.

The welding process is becoming more frequently used in the process of joining two and more elements of constructions. Today, the most frequent use of the welding process is found in the automobile industry, shipbuilding, railroads, offshore industry etc. However, the whole welding process and its wide use in practice bring about the appearance of negative effects, such as the appearance of residual stresses. Considering the complexity of structural elements, besides the presence of residual stresses and the local stress concentration, various flaws in the material itself and the combined loads during the service can lead to failure of structures due to fatigue. The concentration of the stresses appears in the root and in the final passage of welding seam due to geometric discontinuity. Exactly those places are suitable for the appearance of the cracks as a consequence of fatigue. Also, the appearance of residual stresses during the rapid entry of heat and rapid cooling in the zone of welding seam considerably influences the resistance of structures against fatigue. Residual stresses on tension in the structures after the welding process have a negative influence on the behaviour of the structure on fatigue. Unlike residual stresses for tension, residual stresses for pressure can have a beneficial influence on fatigue life of structures. However, the combination of various loads during the service and of residual stresses can positively influence the resistance of structure against fatigue.

In view of the complexity of welding process which encompasses mechanical, thermal and metallurgical phenomena and results in the appearance of residual stresses, the evaluation of the remaining life of welded structures attracts more and more attention amongst engineers and scientists.

Methods in residual life estimations of structures are based on the concept of determining strains, stresses and stress intensity factors.

However, all the methods can be divided into two categories: global and local methods.

The evaluation of the remaining life of welded structures is based on S-N lines, which are presented in the function of nominal stresses and represent a global approach. However, the main flaw of this approach is the lack of differences between nominal and local stresses, as well as the lack of differences between conditions of welding in real conditions and experiments in the laboratory with test specimen to determine S-N lines. Also, this approach is inadequate for the structures exposed to alternating loads and a large number of cycles.

By developing numerical methods, a local approach based on Hot Spot Stress Method, Effective Notch Stress Method and the growth of crack based on LEFM (Linear Elastic Fracture Method) is more and more used in the evaluation of the remaining life of welded constructions. Hot Spot Stress approach is developed in order to determine the resistance of welded structures against fatigue when it is extremely difficult to determine nominal stresses. This approach is applied in determining the resistance against fatigue vessels under pressure and welded structures with circular cross section.

In previous investigations experimental methods have been developed [4-6] to study fatigue life estimation of welded structural elements. In these considerations the effects of discontinuities, geometry, stress ratios, and building materials are analyzed.

There are several approaches and methods for estimating the lifespan both up to initial damage and in the 
presence of cracks. Several approaches exist for predicting fatigue life for welded structures. For initial fatigue life estimation of weldments, including the various effects of influencing this life and the development of a model to study the cyclic relaxation of the residual welding stresses Mattos et al. [7, 8] developed an analytical computation procedure.

\section{THERMOMECHANICAL WELDING MODEL}

Welding can be modelled as a coupled thermomechanical process. Thermal field and high gradient of temperature near weld zone strongly affect stress field. In the first stage, a coupled analysis was represented with a transient heat transfer, based on heat conduction, with a moving heat source, material deposit and temperature dependent material properties. Temperature distribution $T(x, z, y, t)$ is defined by the partial differential equation, with internal heat generation released or consumed per unit volume, $Q_{\text {int }}$, and taking $\rho, K$ and $c$ as a function of temperature only:

$$
\frac{\partial}{\partial x}\left(K_{x} \frac{\partial T}{\partial x}\right)+\frac{\partial}{\partial y}\left(K_{y} \frac{\partial T}{\partial y}\right)+\frac{\partial}{\partial z}\left(K_{z} \frac{\partial T}{\partial z}\right)+Q_{\mathrm{int}}=\rho C \frac{\partial T}{\partial t}
$$

where $\rho$ is material density, $K_{x}, K_{y}, K_{z}$ coefficients of thermal conductivity and $C$ mass-specific heat capacity.

To solve Eq. (1), initial and boundary conditions are needed, respectively:

$T(x, y, z, 0)=T_{0}(x, y, z)$

$\left(K_{x} \frac{\partial T}{\partial x} N_{x}+K_{y} \frac{\partial T}{\partial y} N_{y}+K_{z} \frac{\partial T}{\partial z} N_{z}\right)+q_{s}+$

$+h_{c}\left(T-T_{0}\right)+h_{r}\left(T-T_{r}\right)$

where, $N_{x}, N_{y}, N_{z}$ represent directions normal to the boundary, $q_{s}$ is the heat flux (welding heat source), $h_{c}$ and $h_{r}$ are convection and radiation heat transfer coefficients, respectively, $T_{r}$ is temperature of radiation heat source, and $T_{0}$ is surrounding temperature. Heat losses due to radiation are important only close to the weld, defined as:

$q_{r}=\beta\left(T-T_{0}\right)+\varepsilon \beta\left(T^{4}-T_{0}^{4}\right)$

where $\beta$ is convection coefficient; $\varepsilon$ emissivity of pipe surfaces, and $\beta=5,67 \times 10^{-8} \mathrm{~W} / \mathrm{m}^{2} \mathrm{~K}^{4}$ Stefan-Boltzmann constant. Away from weld zone, the radiation heat losses decrease, whereas convection heat loss increases. The total heat input during the welding process, $Q_{\text {total }}$, comprises volume flux, $Q_{\text {volume, }}$ surface flux, $Q_{\text {surface, }}$, and the energy released when the filler material is cooled from $1500^{\circ} \mathrm{C}$ to $20^{\circ} \mathrm{C}$. The power balance is given by Eq. (5):

$Q_{\text {total }}=Q_{\text {deposite }}+Q_{\text {volume }}+Q_{\text {surface }}=\eta U I$

where $\eta$ is arc efficiency, $U$ and $I$ are arc voltage and current, respectively.

\subsection{Mechanical Model}

Resulting temperature history is used as the thermal loading for residual stress calculation in the subsequent transient thermo-mechanical analysis. The equilibrium equation can be expressed as:

$\sigma_{i j, j}+\rho b_{i}=0$

$\sigma_{i j}=\sigma_{j i}$

In Eq. (6) and Eq. (7) $\sigma_{i j}$ is the stress tensor, $\rho$ density and $b_{i}$ is the body force. In numerical simulation, thermoplastic constitutive equations are used:

$[d \sigma]=\left[D^{e p}\right][d \varepsilon]-\left[C^{\text {th }}\right] \mathrm{dT}$

$\left[D^{e p}\right]=\left[D^{e}\right]+\left[D^{p}\right]$

In Eq. (8) and Eq. (9), [ $\left.\boldsymbol{D}^{\boldsymbol{e}}\right]$ is elastic stiffness matrix, $\left[D^{p}\right]$ plastic stiffnes matrix, $\left[\boldsymbol{C}^{\mathbf{t h}}\right]$ thermal stiffness matrix, $[\boldsymbol{d} \boldsymbol{\varepsilon}]$ strain increment and $\mathrm{d} T$ temperature increment.

\section{INITIAL FATIGUE LIFE ESTIMATION OF WELDED COMPONENTS}

One of the primary goals is the initial assessment of the fatigue life of welded structures. To determine fatigue life of welded joint thefollowing computation procedure is used: FEM for tress analysis, $\varepsilon-N$ relations (deformationlife vs. number of cycles) and introduction of residual stresses effects.

Various criteria can be used for initial fatigue life estimation of welded structural elements subjected to cyclic loads. In this paper, Smith-Watson-Topper (SWT) [9] criterion was chosen because it includes the influence of mean stresses in the estimation of the lifetime. The relation for the SWT criterion is defined in the following form:

$P_{S W T}=\left(\sigma_{\max } \frac{\Delta \varepsilon}{2} E\right)^{1 / 2}=$
$=\left(\left(\sigma_{f}^{\prime}\right)^{2}\left(N_{f}\right)^{2 b}+E \sigma_{f}^{\prime} \varepsilon_{f}^{\prime}\left(N_{f}\right)^{b+C}\right)^{1 / 2}$

where $P_{S W T}$ is $S W T$ parameter. The influence of mean stresses is taken into account through.

$\sigma_{\max }=\sigma_{\mathrm{m}}+\frac{\Delta \sigma}{2}$

In previous relations, Eq. (10) and Eq. (11), low cyclic fatigue properties of material: $\sigma_{f}^{\prime}, N_{f}, b, \varepsilon_{f}^{\prime}, t, c$ are used. For initial fatigue life estimation of welding joints it is necessary to determine these material properties for base metal (BM), weld metal (WM) and heat-affected zone (HAZ). 


\section{NUMERICAL VALIDATION}

Numerical examples are included to verify the calculation procedure for estimating the initial fatigue life of welded joints. In this study, two types of welded joints were considered. The first refers to two butt-welded plates and the second to two butt-welded pipes.

To study initial fatigue life of welded structural components two types of welding problems are considered here: butt-welded joints and cylindrical welded tubes.

\subsection{Initial Fatigue Life Estimation of Butt-Wided Components}

As pointed out above, the first example refers to the estimate of the fatigue life to initial damage for two buttwelded plates loaded with a cyclic load of constant amplitude as shown in Fig. 1. These welded plates are under cyclic external tension loads in which $S_{\max }=146,44$ MPa and $R=S_{\min } / S_{\max }=0$. Material of these plates is ASTM A36 [10], Tab. 1.

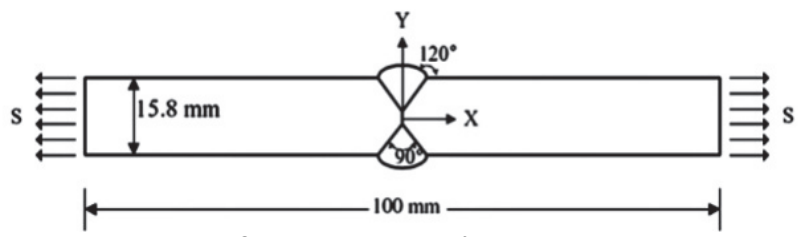

Figure 1 Geometry and loads of butt-welded plates

Table1 Low cyclic fatigue properties of Base, Weld and Heat-Affected Materials

\begin{tabular}{|c|c|c|c|}
\multicolumn{4}{|c|}{ (A36 Welds) } \\
$\begin{array}{c}\text { Low cyclic material } \\
\text { properties }\end{array}$ & A36-BM & A36 HAZ & A36-WM \\
\hline Cyclic strain hardening, $n^{\prime}$ & 0,249 & 0,215 & 0.155 \\
Cyclic strength coeff., $K^{\prime}$ & $1096 \mathrm{MPa}$ & $1489 \mathrm{MPa}$ & $1007 \mathrm{MPa}$ \\
Fatigue strength coeff., $\sigma_{f}^{\prime}$ & $1013 \mathrm{MPa}$ & $724 \mathrm{MPa}$ & $904 \mathrm{MPa}$ \\
& 0,271 & 0,218 & 0.607 \\
Fatigue ductility coeff., $\varepsilon_{f}^{\prime}$ & $-0,132$ & $-0,066$ & -0.075 \\
Fatigue strength exponent, $b$ & $-0,451$ & $-0,492$ & -0.548 \\
Fatigue ductility exponent, $c$ & & & \\
\hline
\end{tabular}

The FEM was used to determine both residual stresses and stresses as a consequence of external load. The ANSYS software package [16] was used for this purpose.

The FE model, as well as the distribution of von Misses stresses from external load, are shown in Fig. 2. Evident good agreement computation with experimental results can be seen in Fig. 3.

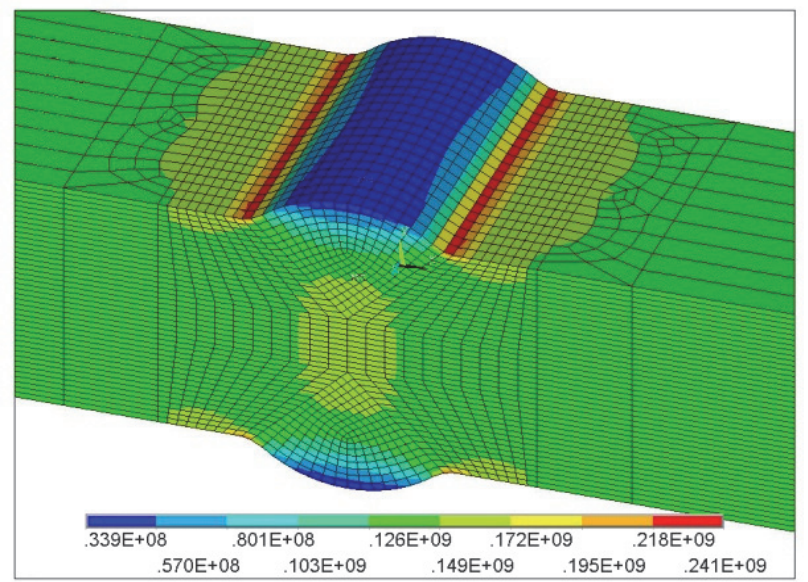

Figure 2 The von Misses stresses distribution under external tension load
Complete von Misses stress distribution in the welded joint zone is shown in Fig. 2. Here are included stresses due to external load and residual stresses due to welding process. The maximum value of residual stresses in the welded joint is $240 \mathrm{MPa}$. The combination of external alternating loads $\left(S_{\max }=146,4 \mathrm{MPa}\right.$ and $\left.S_{\min }=0 \mathrm{MPa}\right)$ are producing stress in the area of concentration of welded joint of circa $280 \mathrm{MPa}$ with residual stresses of $240 \mathrm{MPa}$.

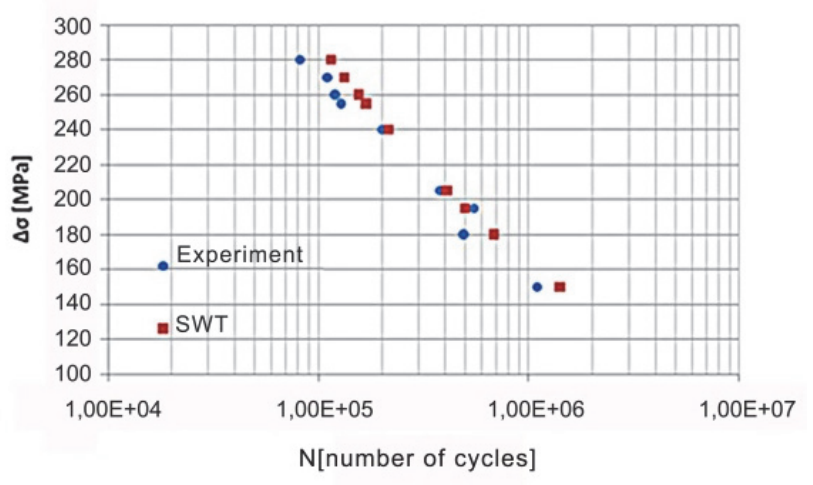

Figure 3 The comparison of present results of fatigue life estimation with experiments [11]

Combining previously determined stresses by FEM together with the initial fatigue life estimation using Eq. (10) of welded specimen, shown in Fig. 1, is determined. Computation of initial fatigue life estimation is compared with experiments, as shown in Fig. 3. Good agreement computation results with experiments of butt welded joint is evident.

\subsection{Initial Fatigue Life Estimation of Two Cylindrical Welded Tubes}

To study initial fatigue life the problem of two welded tubes under combined thermo-mechanical loads is considered here. For determination of residual and mechanical stresses FEM [12-14] is used.

\subsubsection{Numerical Simulation of Residual Stresses of Two Welded Tubes}

In this paper, a computational approach based on FEM is used and software code ANSYS [16] is employed to determine temperature fields and residual stress distribution induced by welding in A36 steel tubes. Tube lengths are $200 \mathrm{~mm}$, outside diameter $324 \mathrm{~mm}$, and wall thickness 3,96 mm, as shown in Fig. 4.

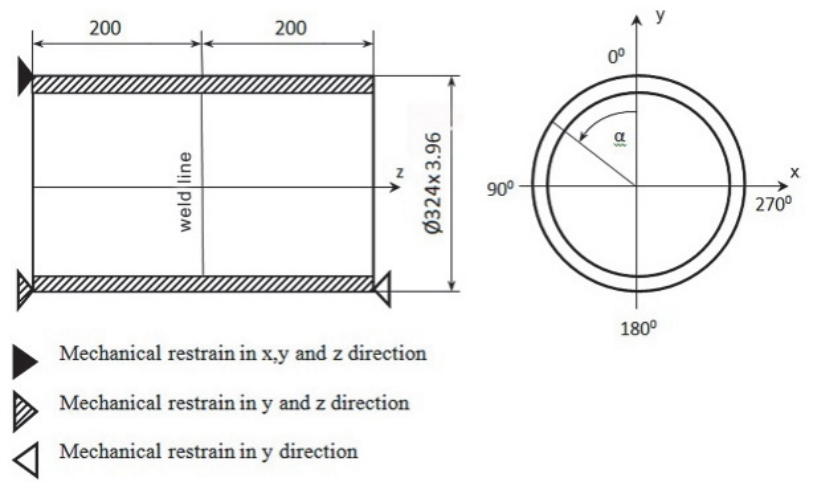

Figure 4 Geometry properties of tubes and boundary conditions 
For the accurate determination of temperature fields and the residual stress distribution induced by the welding process, a finer mesh is used at the welding zone and its vicinity. The number of division in the circumferential direction is 200. In the finite element model, the number of nodes is 21600 , and the number of elements is 14400 . The finite element model is shown in Fig. 5.

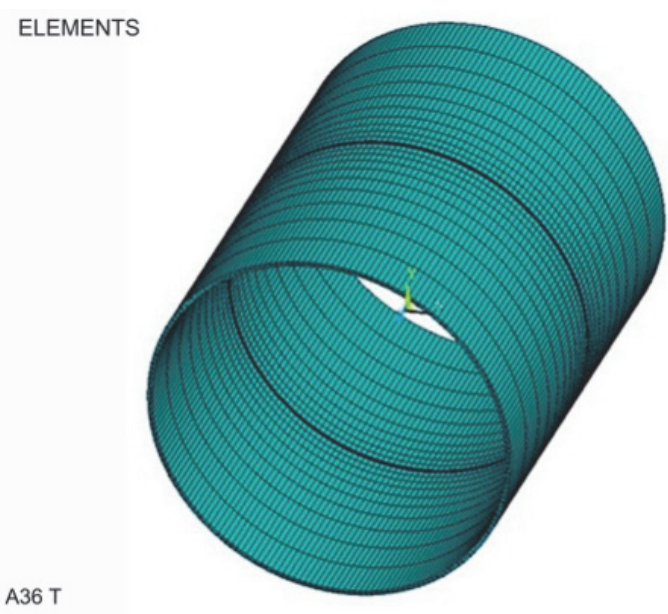

Figure 5 Tube model used for finite elements analysis

Numerical simulations require mechanical and thermal properties for ASTM A36 steel, defined in Fig. 6 and used by ANSYS software code.

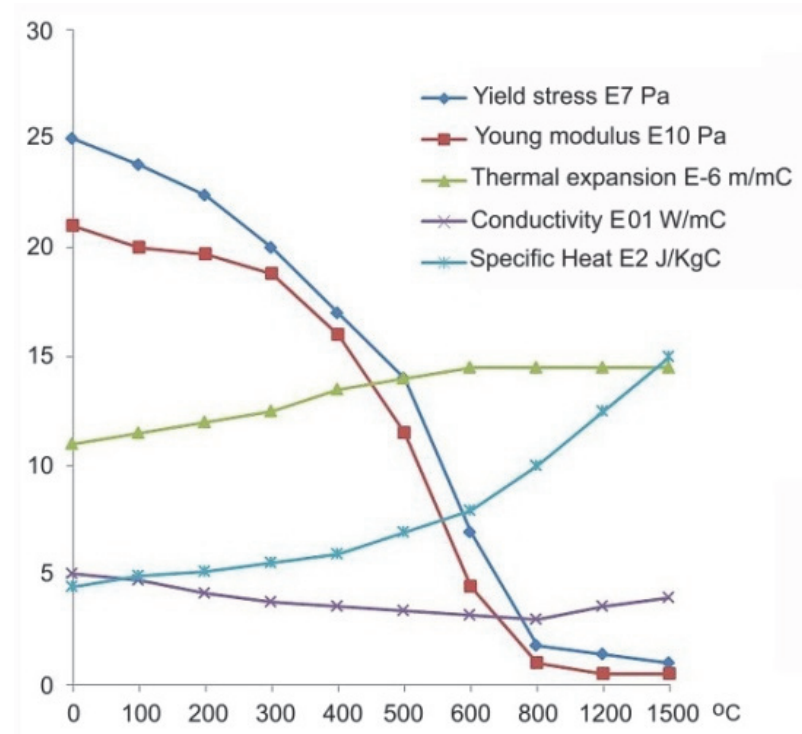

Figure 6 Changing of material properties of ASTM A 36 steel with temperature, [15]

Welding is defined as follows: tungsten inert gas (TIG) process, current $I=110 \mathrm{~A}$, voltage $U=20 \mathrm{~V}$ and speed $v=$ $5 \mathrm{~mm} / \mathrm{s}$. In this numerical simulations the following data is used: convective heat transfer $h_{\mathrm{c}}=15 \mathrm{~W} / \mathrm{m}^{2} \mathrm{~K}$, arc efficiency $\eta=70 \%$, emissivity $\varepsilon=0,8$. Welding of two tubes is carried out in a single pass. The specific heat flux input is $q=2,076$ e10 J/m $\mathrm{m}^{3} \mathrm{~s}$. The joint type was single "V-groove" butt joint with a $1,2 \mathrm{~mm}$ root gap, root face $1,5 \mathrm{~mm}$ and groove angle $60^{\circ}$.

Structural analysis is carried out by ANSYS software code including birth and death elements in process defining of the weld. In this structural analysis the same finite element mesh for mechanical and thermal analyses is used. Different types of finite elements are used for these two types of analysis. In mechanical FE analysis SOLID45 type finite elements are used. In thermal structural analysis SOLID70 type finite elements are used. Fig. 4 shows geometry and boundary conditions that are used in structural analysis by FEM.
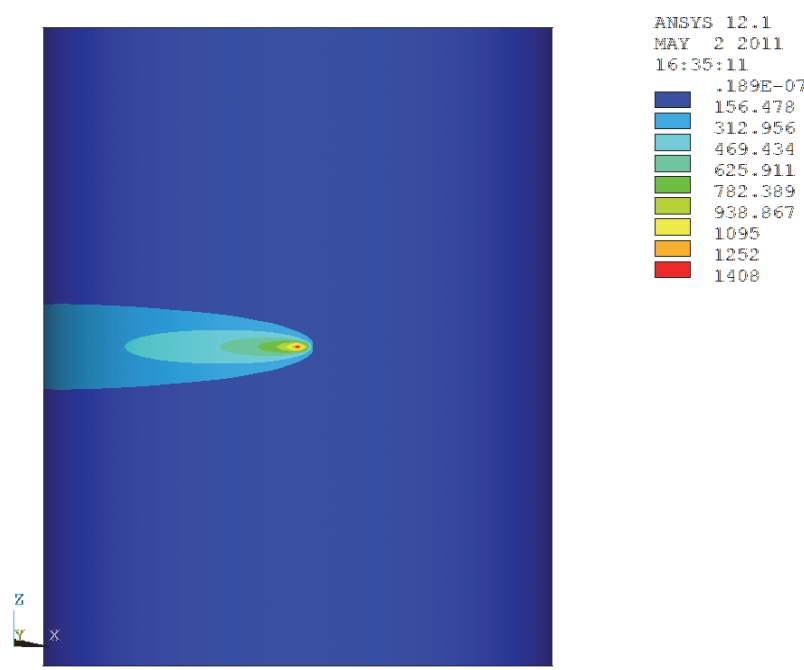

Figure 7 Temperature field $100 \mathrm{sec}$ after start of welding, $\alpha=180^{\circ}$, bottom view

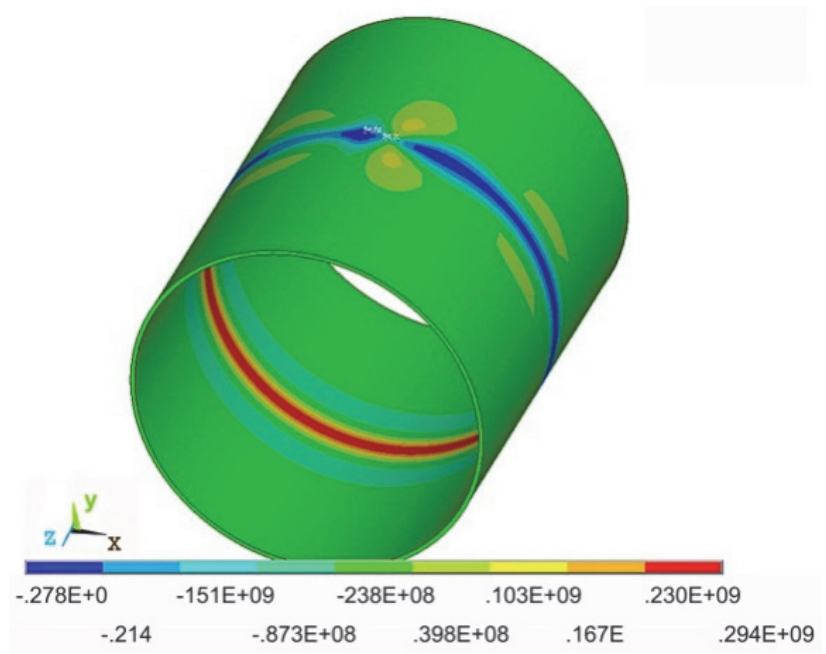

Figure 8 Residual stress distributions in axial direction

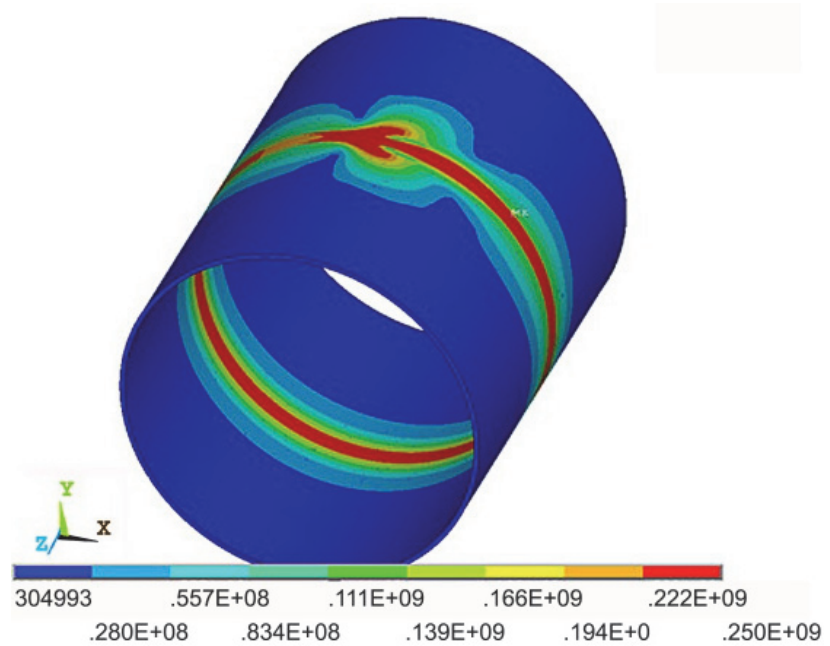

Figure 9 Residual von Misses stresses 
Temperature field induced by moving heat source 100 $\mathrm{s}$ after welding start is shown in Fig. 7. The maximum temperature of the weld bead, $1408^{\circ} \mathrm{C}$, can be seen in this figure. Fig. 8 shows the distribution of the longitudinal residual stress in welded tubes after the material was cooled at room temperature. Detailed stress distributions of the residual stresses after the material was cooled are shown in Fig. 9. Fig. 10 displays compressive residual stresses in the outer surface, respectively.

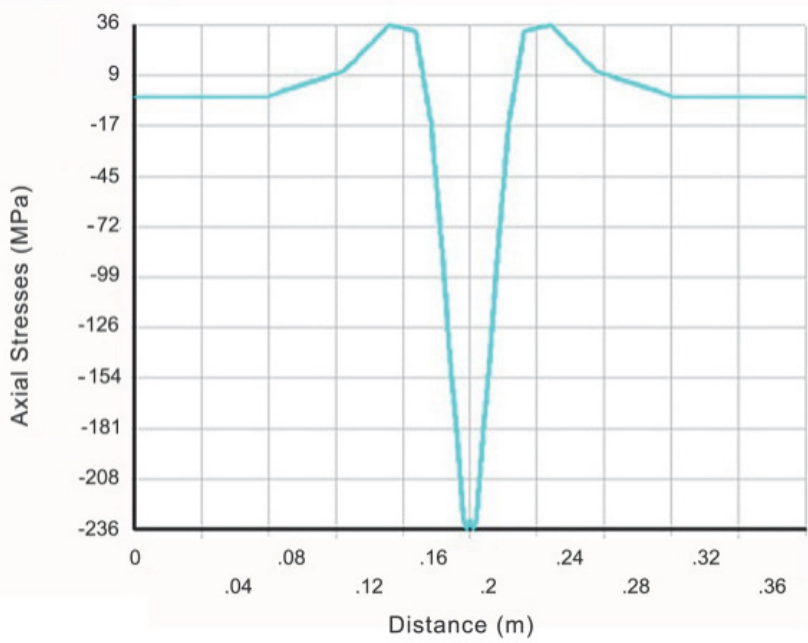

Figure 10 Residual stresses in axial direction on the outer surface of pipes and phase angle $180^{\circ}$

\subsubsection{Initial Fatigue Life Estimation of the Welded Cylindrical Tubes}

The initial fatigue life of welded tubes is considered here, Fig. 4, under combined residual and mechanical loads. To determine initial fatigue life of welded tubes SWT, Eq. (1) is used. Maximal residual tension stress is $251 \mathrm{MPa}$. Combining tension residual stress subjected to external mechanical stress $150 \mathrm{MPa}$ in welding joint initial fatigue life is determined. Material properties of the base material (BM) of cylindrical tubes that are used in initial fatigue life estimation are given in Tab. 1, in accordance with ASTM A36BM [10]. Axial and Von Misses stresses due to thermal and external tension load under $150 \mathrm{MPa}$ are shown in Fig. 11 to Fig. 13. These stresses are incorporated in SWT Eq. (10) to determine initial fatigue life of two welded cylindrical tubes.

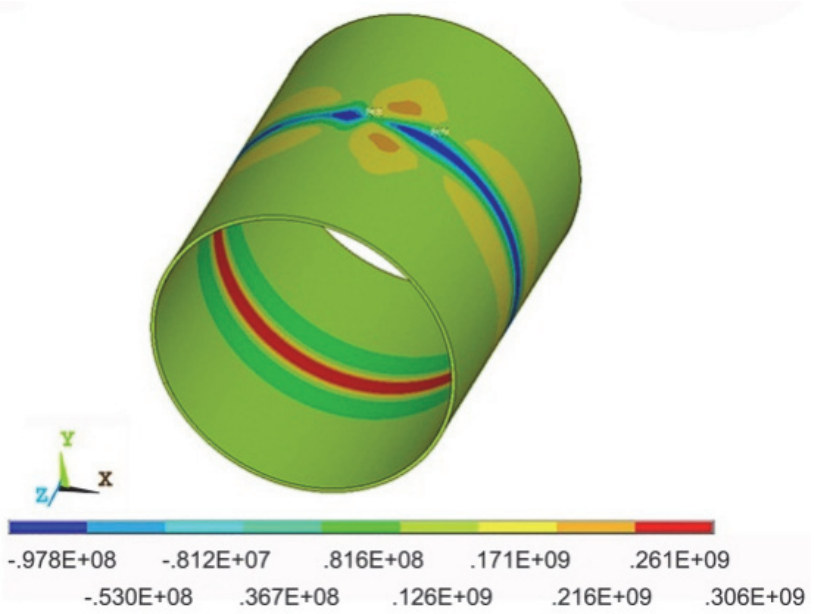

Figure 11 Axial stresses due to thermal and tension load $150 \mathrm{MPa}$
The maximum value of residual stresses in the welded joint is $251 \mathrm{MPa}$. The combination of external cycling loads $\left(S_{\max }\right.$ is changed from value $150 \mathrm{MPa}$ to $80 \mathrm{MPa}$ and $S_{\min }=0 \mathrm{MPa}$ for all cases/for all points in diagram in Fig. 14) with residual stresses of $251 \mathrm{MPa}$. In Fig. 14 is shown initial fatigue life of welded tubes under combined external loads $\left(\Delta \sigma=S_{\max }-S_{\min }\right)$ and residual stresses.

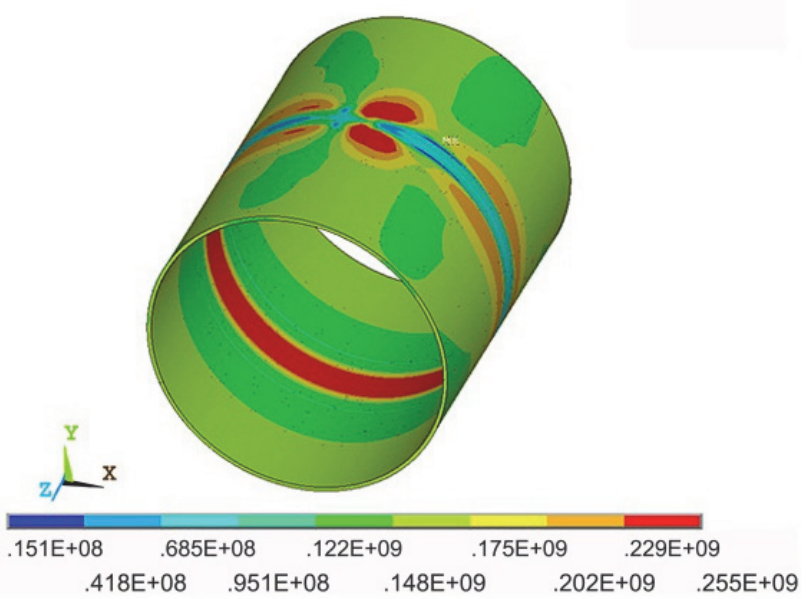

Figure12 Von Misses stresses due to thermal and tension load $150 \mathrm{MPa}$

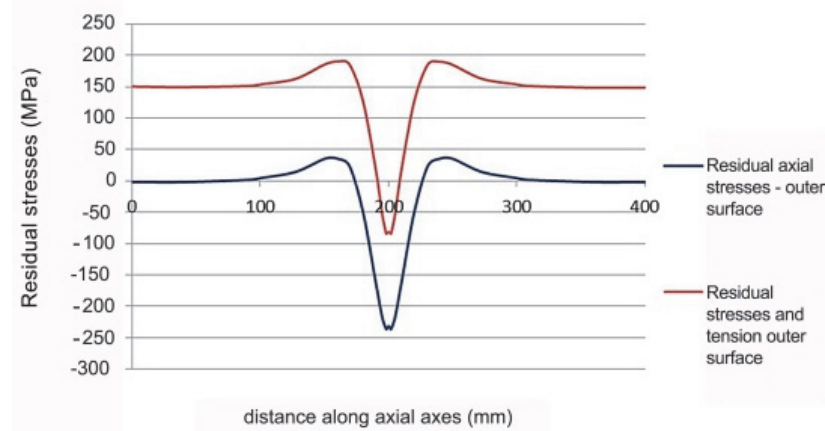

Figure 13 Distribution of axial stresses due to thermal and tension load 150 $\mathrm{MPa}$

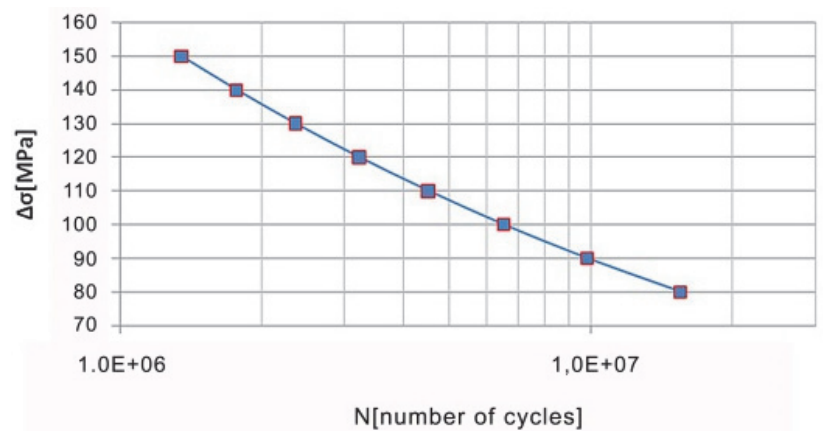

Figure 14 Initial fatigue life estimations of two welded cylindrical tubes under combined mechanical and residual stresses

\section{CONCLUSIONS}

This work considers initial fatigue life of two types of welding constructions; (1) butt-welded components and (2) welded tubes type constructions. In this analysis numerical simulations of residual welding stress modelling and initial fatigue lives estimations of welding type constructions are considered. Special attention in this research is focused to developing reliable computation procedure by using FEM 
for stress analysis and for initial fatigue life estimations of welded structural components.

To verify the validity of the presented results for estimating the fatigue life of the welded joint, comparisons with experiments were made, with the following conclusions:

- FEM is an efficient technique for determination of residual stresses in welding joints.

- Welding was successfully modelled by using FEM and ANSYS software code.

- Initial fatigue life computation procedure of butt welded joints and two welded cylindrical tubes under combined external cyclic loads $\left(\Delta \sigma=S_{\max }-S_{\min }\right)$ and residual stresses using SWT criteria are presented. Good agreement between present computation results with experiments is obtained.

The present computation method is useful also in design, since different process parameters, such as welding speed, number of passes and their sequence, as well as various geometrical constraints and material parameters can be included in this stress analysis and initial fatigue life estimations.

\section{Acknowledgements}

The authors would like to thank the Ministry of Education, Science and Technological Development of the Republic of Serbia for financial support.

\section{REFERENCES}

[1] Deng, D. \& Murakawa, H. (2006). Numerical simulation of temperature field and residual stresses in multi-pass welds in stainless steel pipe and comparison with experimental measurements. Computation Material Science, 37, 269-277. https://doi.org/10.1016/j.commatsci.2005.07.007

[2] Stamenkovic, D. \& Vasovic, I. (2009). Finite Element Analysis of Residual Stress in Butt Welding Two Similar Plates. Scientific Technical Review, 59(1), 57-60.

[3] Bonifaz, E. A. (2000). Finite element analysis of heat flow in single-pass arc welds. Welding Residual Supplement, 121125.

[4] Higashida, Y., Burk D., \& Lawrence F. V. J. R. (1978). Strain-controlled fatigue behavior of ASTM A36 and A514 grade F steels and 5083-0 aluminium weld materials. Welding Residual Supplement. 334-344.

[5] Bowman, M. D. \& Munse, W. H. (1983). Fatigue behavior of welded steel butt joints containing artificial discontinuities. Welding Residual Supplement, 36-44.

[6] Kihl, D. P. \& Sarkanit, S. (1997). Thickness effect on the fatigue strength of welded steel cruciform. International Journal Fatigue, 19, 311-316. https://doi.org/10.1016/S0142-1123(97)00041-8

[7] Mattos, R. J. \& Lawrence J. F. V. (1997). Estimating of the fatigue crack initiation life in welds using low cycle fatigue concepts, SP-424. Society of Automotive Engineers.

[8] Lawrence, F., Burk, J., Mattos, R., \& Higashida, Y. (1978). Estimating the fatigue crack initiation life of welds. ASTM STP 648, 134-158. https://doi.org/10.1520/STP33393S

[9] Smith, K. N., Watson, T., \& Topper, T. H. (1970). A stressstrain functions for the fatigue of materials. Journal of Material, 5, 767-778.

[10] Higashida, Y. \& Lowrence, F. W. (1976). Strain controlled fatigue behavior of weld metal and heat affected base metal in A36 and A514 steel welds. A Report of the Fracture Control Program, (22), University of Illinois.
[11] Lawrence, F., Burk, J., \& Yung, J. (1982). Influence of residual stress on predicted fatigue life of weldments. ASTM STP 776, 33-43. https://doi.org/10.1520/STP30097S

[12] Maksimović, S., Maksimovic, M., Maksimovic, K., Vasovic, I., \& Stamenkovic, D. (2019). Numerical and Experimental Stress Analysis of Layered Composite Structures Subject to Mechanical and Hygrothermal Loads. Structural Integrity and Life, 19(1), 45-49.

[13] Vasovic, I., Maksimovic, S., Stamenkovic, D., Stupar, S., Maksimovic, M., \& Bakic, G. (2014). Fracture Mechanics Analysis of Damaged Turbine Rotor Discs Using Finite Element Method. Thermal Science, 18(1), S107-S112. https://doi.org/10.2298/TSCl121107176V

[14] Maksimovic, S., Posavljak, S., Maksimovic, K., Nikolic, V., \& Djurkovic, V. (2011). Total Fatigue Life Estimation of Notched Structural Components Using Low-Cycle Fatigue Properties. Journal Strain, 47(2), 341-349. https://doi.org/10.1111/j.1475-1305.2010.00775.x

[15] Teng, T. L. \& Chang, P. H. (1998). Three-dimensional thermo-mechanical analysis of circumferentially welded thin-walled pipes. International Journal of Pressure Vessels and Piping, 75, 237-247. https://doi.org/10.1016/S0308-0161(98)00031-3

[16] Theory Reference for ANSYS and ANSYS Workbench, ANSYS Inc.Release 14.1

\section{Contact information}

Mirko MAKSIMOVIC, PhD

PUC Belgrade Waterworks and Sewerage,

Kneza Milosa st. 27, Belgrade, Serbia

E-mail: maksimovic.mirko@gmail.com

Katarina MAKSIMOVIC, PhD

City of Belgrade Administration,

Kraljice Marije st. 1, Belgrade, Serbia

E-mail:kmaksimovic@mts.rs

Dragi STAMENKOVIC, PhD

IDS GmbH,

Oberhausen, Germany

E-mail: dragi33@gmail.com

Ivana VASOVIC MAKSIMOVIC, PhD

(Corresponding author)

Lola Institute,

Kneza Višeslava st. 70a,

Belgrade, Serbia

E-mail: ivanavvasovic@gmail.com 